\title{
MATÉRIA E ESPÍRITO NA COSMOLOGIA JONASIANA
}

Matter and spirit in Jonasian cosmology

\section{Lilian S. Godoy Fonseca UFVJM-NEPC/UFMG}

RESUMO: A abrangência temática dos escritos jonasianos é tão surpreendente quanto a profundidade com que os temas são neles abordados. Um bom exemplo dessa afirmação pode ser encontrado num opúsculo intitulado Materie, Geist und Shöpfung, brilhantemente traduzido para o português, Matéria, Espirito e Criação, pelo nosso colega Wendell Lopes. A modesta dimensão da obra quase encobre a densidade filosófica dos artigos ali reunidos. No Prefácio, o próprio Jonas esclarece que a motivação desse ensaio foi um "rascunho sobre o tema Cosmos e o Segundo axioma principal” (p. 9) que um amigo lhe enviou para uma leitura crítica. Ao responder a tese central do artigo, Jonas se deixou levar por uma reflexão mais profunda que resultou nos 18 artículos ali reunidos. Desses, os dois primeiros discutem o conceito inicial do título (a questão da matéria), os três seguintes, a noção do espírito e do 6 ao 16 Jonas se dedica à reflexão sobre Deus ${ }^{1}$. Dada a complexidade do último tópico, na presente exposição, pretende-se fazer apenas uma breve introdução à cosmologia jonasiana abordando somente os dois primeiros elementos: Matéria e Espírito, deixando a mais extensa discussão sobre a questão teológica, para uma oportunidade futura.

PALAVRAS-CHAVE: Hans Jonas; Cosmologia; Matéria; Espírito.

1. Nos dois últimos, Jonas propõe duas questões: a primeira sobre a possibilidade da filosofia especulativa (17) e sobre a relevância de se saber da existência de outras formas de vida inteligente no universo (18). 


\section{INTRODUÇÃO}

Para iniciar nossa exposição, é preciso evocar o contexto da obra Matéria, Espírito e Criação, exposto em seu Prefácio, lembrando que o seu principal mote foi um "rascunho" sobre o tema cosmos e o segundo axioma principal enviado a Jonas por seu amigo Max Himmelheber, para sua apreciação.

Partindo dessa motivação inicial, Jonas buscará explicar a tendência da matéria para criar das formas inferiores às superiores, ou seja, os organismos (desde os mais simples, até os mais complexos). Ele considera ser esse o primeiro passo para uma concepção cosmológica mais elaborada.

A hipótese defendida por Himmelheber é a de que no momento original do universo (identificado à explosão primordial), além da energia total do cosmos, surgiu também a informação, que Jonas, recorrendo à tradição grega, identifica ao logos cosmogônico, que ele entende como complementar ao conceito de eros cosmogônico, proposto por Ludwig Klages.

Jonas, inicialmente, apenas pretendia discordar do uso feito dos conceitos de informação ou logos por meio de uma breve carta e não responder com um ensaio inteiro. Mas, sem perceber, ao buscar esboçar uma contraposição aceitável, foi conduzido a uma especulação cosmogônica, no interior da qual se articularam "décadas de reflexões sobre ontologia e filosofia da natureza" (MEC, p. 10).

A breve carta cedeu lugar, assim, ao ensaio Materie, Geist und Shöpfung [Matéria, Espirito e Criação (MEC)], cujo motivo inicial explica o fato de ele começar pela contestação de uma hipótese. A partir daí segue, porém, um caminho próprio, retomando reflexões anteriores que, após longo período, voltariam a incitar o pensador.

Nesse ínterim, o "rascunho" inicial de Himmelheber ganhou forma no artigo intitulado “Die Trinität der Natur", publicado em 1988, no número 18 da revista Scheidewege, onde Jonas também publicou uma versão abreviada do MEC que, em maio do mesmo ano, ele proferiu como a terceira palestra do Congresso Internacional "Espírito e Natureza", realizado em Hanover.

Acerca do MEC, Jonas faz três considerações prévias relevantes. A primeira refere-se ao fato de seu tema central ter sido trabalhado mais detalhadamente em outros textos, que ele indicará ao longo do escrito, sempre que necessário.

A segunda refere-se à sequência das palavras do título: matéria, espírito e criação que refletem o curso de sua investigação, da qual resultaram os 18 artículos que compõem o volume, divididos, vale lembrar, da seguinte forma: os dois primeiros discutem o conceito inicial do título (a questão da matéria), os três seguintes, a noção de espírito; do 6 ao 16 Jonas se dedica à reflexão 
sobre Deus e, nos dois últimos, ele aborda duas questões de naturezas distintas, mas igualmente complexas: a primeira sobre a possibilidade da filosofia especulativa (17) e a segunda sobre a relevância de se saber se existem outras formas de vida inteligente no universo (18).

A terceira e última consideração prévia feita por Jonas refere-se ao aspecto metodológico, e ele afirma que

\begin{abstract}
$\mathrm{Na}$ exposição dos dados cosmológicos, portanto, avançamos do externo para o interno, e isto que dizer, desde o ponto de vista da história do ser, do anterior para o posterior; do ponto de vista quantitativo, do mais frequente para o mais raro; do ponto de vista estrutural, do mais simples para o mais complexo e, em termos de apreensão, do ver e sentir para o pensar - e deste pensar, enquanto mais interno, mais raro, e mais tardio, retornamos àquilo que é primeiríssimo, precedendo, inclusive, a matéria: dos dados cosmológicos para a conjectura cosmogônica... (MEC, p. 11) ${ }^{2}$
\end{abstract}

Como já antecipado, considerando a complexidade dos temas ali discutidos e o objetivo da presente exposição: fazer uma breve introdução à cosmologia jonasiana, apenas os dois primeiros elementos - Matéria e Espírito - serão aqui abordados, ficando a mais extensa discussão sobre a questão teológica, para uma oportunidade futura.

A apresentação será dividida em duas partes a primeira dedicada à exposição acerca do surgimento da Matéria e a segunda à exposição acerca do surgimento do Espírito, seguidas de breves considerações finais.

\title{
1) O SURGIMENTO DA MATÉRIA
}

Ainda no Prefácio à obra MEC, Jonas antecipa a perspectiva a partir da qual sustentará sua posição para contestar a tese de Himmelheber, ao dizer: "Na exposição dos dados cosmológicos, o fator evolutivo é decisivo e, em relação à substância do mundo (Weltmaterie), sempre igual e subjacente a tudo" (MEC. p.11).

Essa premissa inicial levanta, porém, uma questão primordial, assim por ele formulada: "a partir de que princípio de progresso pode ser explicada a sua evolução, cósmica em geral e só depois especificamente terrestre, até as formas mais sutis do mundo orgânico?” (MEC. p.11).

Jonas reforça a dificuldade da questão acima, apontando o fato desconcertante de que, seja qual for o princípio que tenha iniciado esse longo processo de evolução, ele o fez contrariando a "lógica" entrópica, que conduz necessariamente da ordem ao caos. Razão pela qual ele declara: “O enigma aí é a direção fisicamente improvável, e antientrópica, do caos para a ordem (só a [direção] inversa é provável)". (MEC. p. 11)

2. Esse percurso metodológico que Jonas adota faz lembrar a 'regra de ouro', proposta por Descartes em seu célebre Discurso sobre o método, ou seja, a terceira regra ou sintese, etapa em que se deve conduzir a investigação do mais simples para o mais complexo, do que é mais concreto ao que é mais abstrato. 
Em seguida, para finalizar o prefácio, Jonas explicita a questão que está na raiz dessa reflexão. Trata-se da utilidade do conceito de "informação", que ele aqui identifica à ideia de programação, a qual já estaria, segundo Himmelheber, presente no "substrato material do mundo (Weltstoff)", pois, teria surgido na "explosão primordial" e estaria a conduzir "a marcha evolutiva do vir-a-ser do cosmos” (MEC. p.11), desde as partículas elementares às organizações mais complexas.

Cabe notar que temos aqui retomada a questão inicial da filosofia concernente à arqué. Não como a maioria dos pré-socráticos a entendiam, como a busca pelo elemento primordial, mas, como vista por alguns, entre os quais Heráclito, como a busca pelo princípio elementar que gerou o movimento originário de tudo.

Por isso, não sem razão, como já mencionado, Jonas identifica essa "informação" original ao conceito grego de "logos cosmogônico". O que explica, portanto, o título do primeiro capítulo - "Logos cosmogônico? Por que não se pode admitir uma 'informação' na matéria primordial" que fornece, simultaneamente, a pergunta e a resposta propostas por ele.

De saída, Jonas aponta a principal característica que identifica na "informação" para justificar sua recusa, dado que, a seu ver, ela “já requer por si mesma, como seu substrato físico, um sistema diferenciado e estável, tal como o é o sistema molecular completamente articulado e constante do genoma dos seres vivos (ou do mesmo modo, em termos magnéticos, a programação - o software - do computador)." (MEC. p.13. Grifos nossos)

Desse modo, o conceito de informação, como Jonas esclarece, não é causa, mas consequência, resultado, efeito de um tipo de organização prévia, que "se perpetua, mas não se sobreleva" (MEC. p.13). Isso equivale a dizer que a informação, gerada no interior de um sistema, pode se conservar, mas, jamais prescindir ou ser anterior ao próprio sistema que a tornou possível.

Além disso, Jonas adverte que as duas exigências, grifadas acima, para a produção da informação: articulação e estabilidade, não podem ser pressupostas no instante de "total indiferenciação e total dinâmica da (hipotética) 'substância' da explosão primordial - ou de modo geral, no 'caos' - a hipótese de um logos cosmológico ou, de outro modo, toda programação preestabelecida e plano rigoroso, residindo já desde o início no interior da matéria nascente, é descartável como um modelo explicativo da evolução". (MEC. p.13) Sobretudo, porque, como Jonas assinala, toda informação exige uma acumulação (para sua articulação e estabilidade) que não pode ser pressuposta no instante da "explosão primordial".

Assim, ele constata que o conceito de "informação" fracassa tanto do ponto de vista lógico, quanto do ponto de vista "genético", ou seja, com relação à gênese do processo evolutivo que ela deveria elucidar, pois ela não é capaz de explicar "além de si mesma. Para isso, é 
necessário um fator transcendente que seja algo adicional e conduza ao novo. Jonas, então, se pergunta:] O que pode ser esse fator?” (MEC. p.14).

Ele antecipa sua inclinação a considerar que "por um lado, isso acontece de um modo mais trivial e anárquico, por outro, de um modo mais misterioso do que é sugerido pelo conceito de informação ou logos, em si mesmo tão compreensível, postulado retroativamente desde o resultado, mas em última instância determinístico. O primeiro aspecto se refere ao lado físico, e o outro, ao lado mental". (MEC. p.14)

Nesse sentido, Jonas defende que esse princípio ou "fator transcendente" originário não pode ser a informação ou o logos pelo simples fato de que, se assim fosse, todo o processo posterior teria sido determinado, conduzido inteiramente por essa 'mensagem prévia' e ele entende que todo movimento se deu de forma "trivial, anárquica" (na dimensão física: da matéria) e "misteriosa" (na dimensão mental: do espírito).

O que nos leva ao capítulo 2, em que Jonas apresenta "A alternativa ao logos - Do caos à ordem através da seleção natural". E no qual, mais uma vez, encontramos já no título a posição que será defendida por ele.

Assim, partindo daquele momento inicial, identificado ao caos, ou como Jonas o apresenta “do desorganizado e sem propósito no vir-a-ser da organização natural", ele acrescenta que "o fundamento de toda organização na natureza, quer dizer, de uma natureza em geral, encontra-se nas leis de conservação.” (MEC. p.15)

Jonas esclarece que tais leis se impuseram graças ao fato tautológico de que "apenas aquiloque-se conserva (Sich-Erhaltende) conserva a si mesmo". Ademais, a própria "regularidade da natureza" é um efeito "universal" da seleção que, a partir de então, estipula "as regras para as novas seleções, mais específicas e locais." (MEC. p.15)

Portanto, a origem das próprias leis da natureza remonta ao instante em que, no interior do "não regular", se precipitaram as primeiras "entidades estáveis, relativamente duradouras, que se comportam sempre (ou por longo tempo) da mesma forma e, desse modo, 'se impõem'.” (MEC. p.15) O que representa, para Jonas, o exemplo mais primordial da sobrevivência do mais apto.

Isso significa que "A ordem é mais bem-sucedida que o caos." (MEC. p.15) Pois, aquilo que não obedece a qualquer regularidade pode, em algum momento, ganhar existência, mas sucumbe, mais cedo ou mais tarde, devido à sua própria fugacidade. Enquanto o que é regular se mantém e vem a predominar. De modo que, de novo tautologicamente, “o transitório dá lugar ao duradouro exatamente por causa de sua transitoriedade.” (MEC. p.15).

Jonas atribui, assim, à lei da conservação o processo de "formação e proliferação dos prótons e, com eles, o domínio da gravitação e da mecânica; dos átomos de hidrogênio até o aparecimento dos 
elementos da tabela periódica e da química (inclusive a beleza dos cristais), em suma o reino da matéria". (MEC. pp.15-16.)

Todavia, Jonas reconhece que, tendo como origem o que é transitório, mesmo essas partículas elementares, embora extremamente duradouras, são também transitórias. Pois, ainda que seus "ciclos" se estendam imensamente como aqueles, por exemplo, das galáxias, das estrelas, dos sois e mesmo os da própria Terra, em algum momento, todos eles terão fim.

Isso levaria à incômoda questão: "para que então a evolução?” (MEC. p.17). Já que é para acabar, por que o cosmos não se conteve com aqueles elementos duráveis, mas "evoluiu" em direção às formações mais complexas, mas, também, mais "instáveis”? Jonas recorre a Darwin, (seu grande inspirador nessa reflexão) para responder que: "sempre permanece 'desorganização' suficiente para, ao acaso cego e isolado, somarem-se novas características (fatores estruturais) às formações existentes, ficando os acertos momentâneos sujeitos ao processo de seleção da evolução com seu critério meramente diferencial-numérico de sobrevivência.” (MEC. p.17).

O mais relevante é, porém, o que vem a seguir, quando Jonas afirma: "Este é o 'fator transcendente' requerido que conduz ao novo e então ao superior - sem pré-informação, sem logos, sem plano, e até mesmo sem impulso, mas apenas através da susceptibilidade de uma organização dada, que já é codificada de 'informação', à desorganização circundante que se the impõe como informação adicional”. (MEC. p.17).

Dito de outra maneira, Jonas encontra no mecanismo da seleção natural o fator transcendente que "age" de modo trivial e aleatório, "organizando" o caos para criar novas formas, deixando sempre um resto de indeterminação prenhe de novas possibilidades.

Com esse "fator", Jonas pondera, seria possível, explicar a progressão dos níveis mais elementares da matéria "até as formas de vida (...) mais complexas e sutis" se, como propôs Descartes, "elas não fossem mais que autômatos mecânicos". (MEC. pp. 17-18).

Todavia, como Jonas ressalta, "elas não são isso, mas algo mais" e a própria atividade de reflexão que está em curso, assinala um aspecto improvável, mas, paradoxalmente, inegável que vem a ser: a interioridade, ou subjetividade ou, ainda, consciência. E cujo surgimento, embora não possa ser explicado nem mesmo pela "mais completa e contínua descrição objetiva do cérebro, mesmo em suas estruturas mais finas e modos de funcionamento", segundo Jonas, será preciso "incluir ... em nossa imagem do universo, ... uma vez que ela tem origem no curso dos eventos naturais e aparece em forma natural..." (MEC. p. 18).

Eis o grande enigma que Jonas espera, então, enfrentar nos três próximos capítulos e sobre o que nos deteremos na segunda parte de nossa exposição.

\section{2) DA CONSCIÊNCIA AO ESPÍRITO}


Já no início do capítulo 3, intitulado, precisamente, "O enigma da subjetividade", Jonas adverte que se chega, assim, "ao misterioso, ao transfísico e ao imaterial”, pois, a subjetividade é um "dado ontológico fundamental no ser" (MEC. p. 19), indispensável para torná-lo completo, ao possibilitar toda e qualquer "manifestação de interesse, finalidade, objetivo, aspiração e desejo ... vontade e valor" (MEC. p. 19) e, por isso, reabre-se a questão teleológica, que parecia superada em favor da causalidade eficiente, suficiente apenas para explicar os "dados meramente físicos" (MEC. p. 19).

Entretanto, Jonas constata que o surgimento da interioridade (e com isso da subjetividade) na "esfera da vida, nos organismos, é um fato empírico" (MEC. p. 19). E ainda que seja fácil explicar o surgimento da dimensão orgânica a partir das propriedades físico-químicas que compõem a sua matéria, não é nada simples explicar o aparecimento da dimensão interna que se abre com o próprio processo de constituição dos organismos.

Nada há previamente na matéria que permita explicar a erupção da subjetividade e, por outro lado, não se pode simplesmente acrescentá-la post factum. Nem há qualquer "denominador comum" entre a "extensão" e a "consciência" (res extensa e res cogitans) e, entretanto, "elas existem juntas, não apenas uma ao lado da outra, mas de forma interdependente, uma interagindo com a outra e, mais exatamente, absolutamente, na "matéria" e (...) de forma inseparável (pois não temos qualquer experiência de um espírito sem corpo)." (MEC. p. 20).

Essa intrigante constatação, que ecoa o célebre dualismo cartesiano, conduz a duas questões cruciais: "Como pode o pensamento fazer frente a uma coisa como essa? [e] Que aparência deve ter uma doutrina do Ser para que faça justiça a tal enigma”? (MEC. p. 20).

Jonas nos relembra a longevidade dessa discussão que resultou em duas perspectivas: as dualistas e as monistas. As dualistas prevaleceram nas concepções metafísicas e religiosas: com Platão, Pascal e Kierkegaard no primeiro caso, Zaratustra, São Paulo e Santo Agostinho passando pelos órficos e gnósticos, no segundo; tendo, porém, em comum o fato de priorizarem a dimensão da alma em relação ao corpo.

Porém, Jonas entende que esse tipo de dualismo sucumbe frente ao "fenômeno da vida orgânica" que revela a indissociabilidade entre os dois, o que torna a radical separação cartesiana insustentável. Não há um corpo (vivo) sem alma e nem uma alma (consciência pura) sem corpo.

Jonas, assim, rejeita a concepção dualista cartesiana, mas, com isso, também a célebre visão socrático-platônica da "imortalidade da alma individual". (MEC. p. 21). 
Sua rejeição ao dualismo não significa, porém, sua adesão a um monismo que tende ao puro materialismo suprimindo a alma, o espírito e a consciência do fenômeno vida, restringindose a processos "físicos" que ocorrem no cérebro.

Jonas reconhece que esse monismo tem ainda mais problemas que o dualismo, mas, ainda assim, pretende buscar uma solução monista para tal "enigma, já que a voz da subjetividade nos animais e nos seres humanos emergiu dos mudos torvelinhos da matéria e a ela continua a se ligar." (MEC. p. 21).

Desse modo, apesar da grande dificuldade da questão e de seu alto teor especulativo, Jonas não se intimida e prossegue afirmando que

é a própria substância do mundo que, ao tornar-se interior, ganha, com isso expressão. (...) O que parece necessário, então, para a solução monista, é uma revisão ontológica, uma renovação do conceito de matéria para além da mensurabilidade exterior da física e que introduza novamente aqueles conteúdos que foram extraídos dela - portanto, uma meta-física do substrato material do mundo. (MEC. pp. 21-22).

Contudo, ele esclarece que oferece apenas uma exposição conjetural com o objetivo de submeter suas proposições, resultantes de décadas de reflexão, a exame.

Assim, já no início do capítulo 4, intitulado "Em que o dado da subjetividade contribui para os dados cosmológicos?", Jonas afirma que "o mínimo que devemos conceder à matéria que se desenvolveu a partir da explosão primordial, tendo em vista o que, por fim, surgiu depois, é uma disposição original com a possibilidade eventual de interioridade - não uma disposição com interioridade, nem mesmo uma disposição para a interioridade no sentido de já estar preparada para ela.” (MEC. p. 23).

Ou seja, ele explicita que a "potencialidade para algo" não pode ser confundida com o "serdisposto para algo" que pressupõe uma orientação prévia para uma "certa direção". Assim, a explicação de Jonas mantém-se modesta o suficiente para afirmar simplesmente que "a emergência de uma dimensão interior quando e onde quer que tenha ocorrido, e de sua existência real e presente em nós, é apenas o resultado quase trivial de que essa dimensão era 'possível' segundo as características da matéria como originalmente 'criada'." (MEC. p. 23).

Aqui, porém, a reflexão se complexifica, pois, conduz a duas questões desconcertantes: “quem (ou o quê) 'dispôs' a matéria de tal maneira? E: que porção teve essa 'disposição' no curso dos acontecimentos do mundo?" (MEC. p. 24) Estamos, aqui, diante da questão relativa à "vontade criadora" e de sua ação posterior no mundo.

Jonas pede cautela quanto ao uso do termo 'vontade' atribuído à causa primeira, mas, ainda assim, sustenta que é impossível supor que algo não indiferente (como a subjetividade) tenha se

3. Posição que, atualmente, tende a prosperar, pois há toda uma corrente da neurociência que, como se sabe, se ocupa precisamente de estudos que visam explicar até mesmo o "comportamento ético", unicamente, através das operações neuronais, a chamada "neuroética". 
originado de algo completamente "indiferente e neutro". (MEC. p. 24). É preciso supor, ao menos, uma espécie de "preferência favorável" já no "cerne da matéria", mesmo que sem um "plano" pré-determinado (o que foi de antemão descartado), mas como uma "tendência, um anseio, que se aproveita da oportunidade de uma causalidade do mundo e logo a leva adiante." (MEC. p. 24). E aqui Jonas oferece uma alternativa, quase poética, ao dizer que "um eros cosmogônico se aproxima mais da verdade do que um logos cosmogônico". (MEC. p. 24).

Ainda assim, ele afirma que todo o movimento se segue entregue ao acaso e, apesar do improvável, sempre que as condições favoráveis (como a vida no planeta Terra) se oferecem, a disposição se manifesta e se faz ato (para usar, aqui, uma terminologia aristotélica!). Desse modo, não é o puro acaso que está em jogo no improvável fenômeno de surgimento da vida.

Essa explicação jonasiana faz eco com algumas explicações pré-socráticas (como as de Empédocles, Heráclito e Parmênides) que atribuem às divindades (do Amor e do Ódio) a ação inicial que reuniu ou separou os elementos para a constituição do cosmos. Mas, também, se aproxima à noção freudiana de Eros e Tânatos, como pulsão (impulso) de vida e pulsão de morte.

Tais aproximações, talvez, possam tornar mais compreensível a afirmação de Jonas de que "a vida é um fim para si mesma” [quase que por esse 'impulso' que a projeta e conduz]. Sendo "um fim que se quer e se persegue ativamente". (MEC. p. 25).

Nesse sentido, Jonas pode, então, declarar que "desde a origem, a matéria é subjetividade em estado latente, ainda que éons, somados a uma sorte excepcional, tenham sido necessários para a atualização desse potencial.” (MEC. p. 24). Ele acrescenta que o testemunho da vida nos abre um caminho em direção à teleologia.

Ele resume todo o seu argumento, até aqui, dizendo que estando a finalidade presente nos seres vivos, inicialmente de forma subjetiva, para se efetivar objetivamente e causal, ela não pode estar ausente na natureza, de onde ela emerge. Daí, Jonas pode extrair não apenas a presença de fins na natureza, mas a própria dimensão do valor.

Jonas ressalta ainda que toda essa reflexão foi possível sem recorrer a uma transcendência, apenas à "voz da imanência que fala por si mesma." (MEC. p. 27).

Todavia, até o momento, o espírito, propriamente dito, ainda não emergiu e é no capítulo 5 que ele vai discutir a interessante questão da "Liberdade transcendente do espírito".

Jonas começa explicitando que quem está realizando essa reflexão somos nós mesmos ou, melhor, o nosso pensamento [lembramos aqui o cogito cartesiano]. Assim, "ao testemunho vital é acrescido o testemunho antrópico e, com isso, certamente se abre um horizonte de transcendência" (MEC. p. 29), que se manifesta triplamente na "liberdade do pensar": 1) Liberdade de autodeterminação do pensamento (ele próprio define sobre o que pensar). 2. Liberdade de transformar o dado sensível em uma imagem interior (liberdade inventiva da imaginação) e 3) Graças à linguagem: 
liberdade de ir além de tudo o que é predeterminado: da existência para a essência, do finito para o infinito, do temporal para o eterno, etc.” (MEC. p. 29).

Jonas declara, a seguir que "Todas as três liberdades são prerrogativas exclusivas do espírito que apontam para o 'transanimal no homem'.” (MEC. p. 30).

E, com essa reflexão, Jonas oferece uma interessante concepção acerca da emergência do espírito, a partir do despertar da consciência que emergiu, por sua vez, da evolução das formas vivas, tornadas possíveis pela explosão primordial que ofereceu a matéria-prima para formar tudo o que existe no universo.

\section{CONSIDERAÇÕES FINAIS}

Para fechar essa exposição, é preciso apontar que não serão apresentadas aqui, como seria de se esperar, uma conclusão nem mesmo considerações finais, no sentido de um arremate definitivo da discussão proposta. Pois, isso implicaria a abordagem dos demais opúsculos do MEC, o que não foi possível dada a limitação de tempo para preparar e apresentar toda a complexa reflexão ali oferecida por Jonas.

Desse modo, como apenas os dois primeiros temas - matéria e espírito - foram então focalizados, o que se propõe, por ora, são mais exatamente meras 'considerações parciais' acerca da cosmologia jonasiana, brilhantemente sintetizada no MEC.

Além de parciais, tais considerações pretendem apenas retomar e sumariar o que Jonas abordou nos cinco primeiros ensaios, visando a preparação para uma futura exposição dos demais ensaios que compõem o volume. Sendo assim, vimos que:

No primeiro ensaio, - "Logos cosmogônico? Por que não se pode admitir uma 'informação' na matéria primordial" -, já no título, Jonas propôs, simultaneamente, uma pergunta e a resposta à tal questão. A premissa que ele assentou foi a de que o traço principal de toda informação é requerer um sistema diferenciado e estável, como seu substrato físico. Destarte, ele defendeu que, para haver uma informação, é necessário um sistema organizado no interior do qual tal informação possa ser constituída.

Nesse sentido, o conceito de informação, como Jonas esclareceu, não é causa, mas consequência, resultado, efeito de um tipo de organização prévia. E como as duas exigências para a produção da informação: articulação e estabilidade, não podem ser pressupostas no instante totalmente indiferenciado e caótico da explosão primordial, "a hipótese de um logos cosmológico ou, de outro modo, toda programação preestabelecida e plano rigoroso, residindo já desde o início no interior da matéria nascente, é descartável como um modelo explicativo da evolução”. (MEC. p.13) 
Portanto, o conceito de "informação", como algo presente na matéria primordial, fracassou tanto do ponto de vista lógico, quanto do ponto de vista "genético". O que nos levou ao capítulo 2, no qual Jonas apresentou "A alternativa ao logos - Do caos à ordem através da seleção natural". Em que, mais uma vez, encontramos já no título a posição defendida por ele.

Assim, partindo daquele momento inicial, identificado ao caos, ou como Jonas o apresentou "do desorganizado e sem propósito no vir-a-ser da organização natural”, ele acrescentou que "o fundamento de toda organização na natureza, quer dizer, de uma natureza em geral, encontra-se nas leis de conservação.” (MEC. p.15)

Vimos que Jonas atribuiu à lei da conservação o processo de "formação e proliferação dos prótons e, com eles, o domínio da gravitação e da mecânica; dos átomos de hidrogênio até o aparecimento dos elementos da tabela periódica e da química (inclusive a beleza dos cristais), em suma o reino da matéria”. (MEC. pp.15-16.)

Entretanto, para além dessa lei da conservação, ele reconheceu que, tendo como origem o que é transitório, mesmo essas partículas elementares, embora extremamente duradouras, são também transitórias. Pois, ainda que seus "ciclos" se estendam imensamente como aqueles, por exemplo, das galáxias, das estrelas, dos sois e mesmo os da própria Terra, em algum momento, tudo isso terá fim.

Chegamos, assim, à incômoda questão quanto à finalidade de todo o processo evolutivo. Pois, já que é para acabar, por que o cosmos não se conteve com aqueles elementos duráveis, mas "evoluiu" em direção às formações mais complexas, mas, também, mais "instáveis"? Jonas, inspirado por Darwin, encontrou no mecanismo da seleção natural o fator transcendente que "age" de modo trivial e aleatório, "organizando" o caos para criar novas formas, suprimindo aquelas menos aptas, deixando sempre, porém, um resto de indeterminação repleto de novas possibilidades.

Embora com esse "fator" tenha sido possível explicar a progressão dos níveis mais elementares da matéria "até as formas de vida (...) mais complexas e sutis" (MEC. p. 17), como Jonas indicou, elas se tornaram algo mais que a mera função biológica e a atividade de reflexão revela um aspecto improvável, mas, paradoxalmente, inegável que é a interioridade, ou subjetividade ou, ainda, consciência.

Com efeito, o surgimento da consciência criou um problema ainda mais desconcertante e, embora não possa ser explicado nem mesmo pela "mais completa e contínua descrição objetiva do cérebro, mesmo em suas estruturas mais finas e modos de funcionamento" (MEC. p. 18), Jonas viu a necessidade de enfrentá-lo em sua cosmologia, pois, a consciência é um fenômeno natural como tantos outros que desafiam o entendimento humano, sendo, entretanto, um dos mais instigantes. 
Esse grande enigma foi enfrentado por Jonas nos três capítulos seguintes e a eles foi dedicada a segunda parte de nossa exposição.

No capítulo 3, intitulado exatamente "O enigma da subjetividade", Jonas iniciou a reflexão acerca do surgimento da consciência e da sua relação com o seu substrato material; retomando, ali, um dos mais intrincados problemas filosóficos, pois, embora a consciência seja um dado empírico, não há nada de antemão na matéria que permita explicar o seu advento. Ainda assim, nosso autor assinalou que ela não pode, simplesmente, ser acrescentada post factum. Logo, era preciso descobrir o que, desde o início, tornou possível a emergência da consciência.

Ademais, nada há em comum entre a "extensão" e a "consciência" (res extensa e res cogitans) e, apesar disso, "elas existem juntas, não apenas uma ao lado da outra, mas de forma interdependente, uma interagindo com a outra e, (...) de forma inseparável (pois não temos qualquer experiência de um espírito sem corpo)." (MEC. p. 20).

Jonas se deparou, então, com o clássico problema cartesiano, reconhecendo que ele já está presente desde Platão e que, ao longo da tradição, as inúmeras tentativas de solucioná-lo podem ser divididas em duas tendências básicas: as monistas e as dualistas. Ele fez críticas às duas posições, mas, assumiu que sua própria concepção tenderia mais ao monismo, ainda que não de tipo radical, e que para superar a separação, então, intransponível entre res extensa e res cogitans seria preciso uma revisão ontológica da dimensão material, reduzida por Descartes e pela Física à sua mensurabilidade.

No capítulo 4, intitulado "Em que o dado da subjetividade contribui para os dados cosmológicos?", Jonas sugeriu que para explicar o advento da consciência, devemos, ao menos, atribuir à matéria resultante da explosão primordial, "uma disposição original com a possibilidade eventual de interioridade - não uma disposição com interioridade, nem mesmo uma disposição para a interioridade no sentido de já estar preparada para ela." (MEC. p. 23).

Ele quis distinguir entre a "potencialidade para algo" e o "ser-disposto para algo" que pressupõe uma orientação prévia para uma "certa direção". Assim, sua explicação se manteve modesta o suficiente para afirmar simplesmente que "a emergência de uma dimensão interior quando e onde quer que tenha ocorrido, e de sua existência real e presente em nós, é apenas o resultado quase trivial de que essa dimensão era 'possível' segundo as características da matéria como originalmente 'criada'." (MEC. p. 23).

Porém, tal suposição tornou ainda mais complexa a discussão ao precipitar duas questões desconcertantes: “quem (ou o quê) 'dispôs' a matéria de tal maneira? E: que parcela teve essa 'disposição' no curso dos acontecimentos do mundo?’ Ou seja, emergiu o problema relativo à "vontade criadora" e de sua ação posterior no mundo. 
E, embora pedindo cautela quanto ao uso do termo 'vontade' atribuído à causa primeira, Jonas ofereceu uma alternativa, quase poética, ao dizer que "um eros cosmogônico se aproxima mais da verdade do que um logos cosmogônico". (MEC. p. 24). Ele ressaltou ainda que realizou toda essa reflexão sem recorrer a uma transcendência, apenas à "voz da imanência que fala por si mesma." (MEC. p. 27).

Contudo, até aqui, não se explicou a emergência do espírito, propriamente dito, e foi no capítulo 5 que ele discutiu a relevante questão da "Liberdade transcendente do espírito".

Jonas começou lembrando-nos que quem está realizando essa reflexão somos nós mesmos ou, mais exatamente, o nosso pensamento [semelhantemente ao argumento do cogito cartesiano]. Desse modo, à dimensão vital foi acrescentada a dimensão antrópica com o que se abriu, necessariamente, "um horizonte de transcendência" (MEC. p. 29), que se manifesta na tripla "liberdade do pensar", assim especificada: "1) Liberdade de autodeterminação do pensamento (ele próprio define sobre o que pensar). 2. Liberdade de transformar o dado sensível em uma imagem interior (liberdade inventiva da imaginação) e 3) Graças à linguagem: liberdade de ir além de tudo o que é predeterminado: da existência para a essência, do finito para o infinito, do temporal para o eterno, etc." (MEC. p. 29)

E como Jonas ressaltou, "Todas as três liberdade são prerrogativas exclusivas do espírito que apontam para o 'transanimal no homem'.” (MEC. p. 30).

Desse modo, por meio dessa brilhante especulação, Jonas demonstrou como se deu o surgimento da matéria (no plano físico e químico), a emergência da consciência (na esfera biológica) e o despertar do espírito (na dimensão antrópica), sem recorrer a qualquer transcendência.

Porém, nos capítulos seguintes (6 a 16), ele dará um passo ainda maior em seu percurso especulativo e enfrentará a árdua questão teológica, na longa reflexão dedicada ao terceiro termo do título, isto é, a Criação.

Embora a questão intrigante de saber como ele conciliará a reflexão que evitou todo recurso à transcendência com a hipótese da criação instigue nossa curiosidade, a resposta ficará para outra oportunidade e, a quem não puder se conter até lá, fica o convite à leitura dessa cativante obra jonasiana.

\section{REFERÊNCIA}

JONAS, Hans. Matéria, Espírito e Criação. Petrópolis: Vozes, 2010. 